\title{
Re-valorizing rubbish: some critical reflections on 'green' product strategies
}

\author{
Neil Maycroft \\ History of Art \& Material Culture \\ Lincoln School of Art \& Design \\ University of Lincoln \\ e-mail: nmaycroft@lincoln.ac.uk
}

This paper was originally published as 'Re-valorizing rubbish: some critical reflections on 'green' product strategies', in Capital $\&$ Class Special Issue; Environmental Politics: Analyses and Alternatives, No 72, Autumn 2000. 


\section{Introduction}

The last twenty years has seen the rise of a series of intellectual and practical responses to environmental degradation. Many socialists and critical theorists have sought to develop sophisticated analyses of ecological despoiling and have aimed to provide the contours of various 'eco-socialist' alternatives. These range from visions of small-scale communal autarky through 'green' or 'eco-city' concepts to global perspectives. Crucially, for most of these ecologically minded socialists, the social relations of capitalism rather than simply the 'industrial mode of production' has been the focus of critique. Where many liberal or reactionary environmentalists see the industrial processes of production and the wasteful activities of consumption as driving the planet towards ecological doom, most socialists seek to analyze the ways in which the relational social processes of capital augment, enlarge and exaggerate the ecological harm that results from industrial production and mass consumption.

It is within this complex context that supposedly 'green' product strategies are promoted by capitalists, environmentalists and some socialists. The advanced industrial economies of the West are the principle national contexts in which such proposals have arisen and they are the focus of this paper. Whilst environmental processes do not recognise national boundaries, it is important to keep in mind the cultural differences which shade these debates within different national contexts. Scandinavian approaches to conceptualising the environment differ from American perspectives, German commitment to recycling can be contrasted to that of the United Kingdom. Therefore, this paper represents a distillation of general points and perspectives with regard to the product strategies discussed. The level of its generality and the plausibility of its speculations need to be constantly oriented within specic geographical and temporal contexts.

The strategies specically considered here are the 'product-service', design for disassembly' (DfD), and the 're-valorizing' of waste. The product-service aims to 'embed' consumer products into webs of services which become the increasing focus of consumption and thus, it is claimed, reduce the need for the consumption of as many manufactured goods. Design for disassembly, along with other similar techniques, is a method of manufacture in which components are assembled in such a way as to make disassembly quick, efficient and convenient. The resulting of disassembled components offers the prospect of 
less resource depletion, energy use, landll waste, etc. Re-valorizing rubbish refers to the combination of waste materials into new commodities with the result being the supposedly more rational, complete and ecologically benecial use of scarce materials. As fostered and developed in advanced capitalist societies, such strategies hold the promise of both maintaining current levels of consumption, and hence the material comfort associated with Western consumerism, and of fostering ecological sustainability via the 'greening' of industrial production. Concepts such as a 'new type of industrialism' and 'Natural Capitalism' have been introduced as a way of imparting a 'green' gloss to what are basically economic modernisation and increased resource productivity programmes (Hawken et al 1999)

As such, these product strategies can be seen as the latest in a series of technocratic solutions, driven by the imperatives of economic rationality, to environmental problems that have come to prominence over recent years. These include the 'greening' of Generally Accepted Accounting Practice', 'Life Cycle Analysis' and 'MIPS'(calculating the material input of a product per unit of service output). Also, 'Eco-labelling' (whether it informs about raw materials, energy use, recycling potential, effect on the environment, etc) which is, in large part, an attempt to rationalise environmental choices into purchasing decisions. Eco-labelling, in particular, is underpinned by the belief that the free market can guarantee environmental protection and ecological sustainability.

Naturally, producers still play upon the rhetoric of 'green' or 'sustainable' consumerism to increase product prices and hence capital accumulation. One of the implications of so called 'sustainable' consumption is that the full ecological costs of the impact of consumption are reected in the price of the product. This provides a powerful ideological pivot around which various ecological claims can be made in order to sustain consumption. Such ideology accords with widespread public concern over the environment. ${ }^{1}$ Hence, the appeal of product strategies that promise increased GNP whilst delivering so called environmental benets is obvious. Substituting supposedly 'green' commodities for ecologically damaging ones is particularly attractive to those who want to enjoy both 'more trees and material goods' (Wallerstein 1997).

Whilst the state generally acts to preserve and guarantee access to envi-

\footnotetext{
${ }^{1}$ For example, recent surveys claim that two thirds of consumers would pay more for products with 'environmental benefits', though what exactly these benefits are remains vague (Cooper 1997).
} 
ronmental resources, there have been some signicant national developments, resulting from compromises between fractions of capital, the labour movement and environmental reformists (Barry 1999). One result of these processes of ecological modernization has been the threat and imposition of legal requirements for taking responsibility for the ecological costs of production. This has driven many manufacturers to seek out new product strategies as ways of off-loading environmental costs. Whilst new taxes have been debated for years, and introduced in various nations, they have tended to be concentrated on the latter stages of the productive process - pollution taxes, landfill taxes, etc. There has been much less implementation of depletion taxes which aim to decrease the levels of resource extraction and material depletion at the beginning of the productive process. Consequently, the increased competition within the recycling sector, which results from the imposition of 'end' taxes can, instead of reducing resource extraction and depletion actually provide the incentive for greater extraction and depletion with all of its attendant social-ecological costs. Hence, re-valorizing strategies provide an attractive way to lessen the impact of 'end' taxes whilst also demonstrating capitalism's sensitivity to the concern over increased depletion. Re-valorization strategies also, then, anticipate the future imposition of depletion taxes and provide a means of lessening their impact too. Similarly, as extraction of resources generally becomes more expensive, which is witnessed in the rising prices of nished goods, recycling becomes more protable and, this also accounts for the interest shown by many producers in this sector. As Ekins points out the damage-control and damage-repair sector thus becomes a new opportunity for growth for national economies' (quoted in Dobson 1991: 163).

Certainly, the strategies discussed here enable producers to pass on the environmental costs of production. However, producers are also looking to generally decrease the costs of production. Hence, the determined efforts to engineer a 'flexible' economy, one in which many of the costs of employment, above and beyond basic wages, have been increasingly externalised by the productive sector. Under the ideology of environmental sustainability these costs can also be passed on to the consumer. Producers increasingly look to consumers to transport, package, assemble, and dispose of finished products and, at each step the costs of these activities are being passed to the consumer. In the near future we may all spend an increasing and regular portion of our lives absorbing costs externalised by producers. These could include the now familiar paying of transport costs associated with food distribution 
(driving to out of town shopping centres), the partial preparation of our own restaurant meals (the 'freedom' to visit the salad-bar in fast-food outlets), to the domestic sorting of refuse and the disassembly of products previously purchased in fully assembled form. From a contemporary Weberian perspective, Ritzer $(1998,1999)$ has argued that these 'new means of consumption' can be seen as attempts to extract surplus value from consumers by turning them into unpaid producers. They represent a shift of productive activities from a clearly dened productive sphere and they contribute to the blurring of the distinction between production and consumption. Whilst Ritzer does not develop his analysis by connecting it to the anti-ecological dynamics inherent in the valorisation imperative of capital, he provides an interesting starting point for further research from this perspective. Evidently, by convincing the consumer that they are being 'empowered' or are 'caring' for the environment, this type of reorganisation of productive relations can be obscured.

Crucially, for socialists, these product strategies need to be critically located within the context of expanding capitalism rather than that of ecological damage limitation or reversal. Capitalist expansion is usually regarded as proceeding via two different strategies: Firstly, geographical expansion via the conquering of new markets, processes of globalisation and, imperialism. Secondly, by increased commodity production and commodity promotion within a market. This proceeds via the development of new lines, product differentiation, stylistic obsolescence (product styling), technical obsolescence, niche marketing, the widespread extension and encouragement of credit, and so on, all of which are aimed at stimulating consumption. However, capitalism also expands by the commodication of its own unintended consequences, 'externalities' or, 'diseconomies'. One example would be the way in which the physical ill-health that results from much work leads to increased consumption of drugs and hence to increased prots for drug companies. Similarly, the mental ill-health that is so strongly prevalent in advanced capitalist societies provides the ever-growing market for drugs such as Prozac. As a result, such diseconomies extend the '... very system that has created the need for them' (Lodziak \& Tatman 1997: 80). In terms of the themes discussed in this paper, it has become clear that a similar argument can be made about the waste that is central to production and consumption in post-necessity capitalist economies. As Gorz argues 'Destruction officially appears as a source of wealth since the replacement of everything broken, 
thrown out or lost gives rise to new production, sales, monetary flows and profits' (1980: 122).

As this paper engages with product strategies that heavily involve design considerations, in terms of both the functional design of commodities and of their symbolic and aesthetic meanings, it is appropriate to consider in more detail the relationship between design, consumption, and the environment.

\section{The role of design}

One of the chief roles of the professional designer in a capitalist economy is to add value to consumer goods. Value is added in various ways. Designers certainly add value in terms of functionality, that is, use-value. Technological advance, better performance, and increased safety are all features of commodities that designers work in general to improve. However, planned technical obsolescence means that many domestic goods are not as durable as they could be. As a result, increased consumption, along with increased environmental impact, is encouraged and necessitated as items malfunction and as lines of goods rapidly change (which works against nding either spare parts or exact replacements). In this way design actually destroys use-value.

Designers also add exchange-value. Indeed, in the 1980s the sobriquet 'designer' was enough by itself to add both exchange-value and status to all manner of consumer paraphernalia. The name of a famous designer is a powerful talisman behind which the price of commodities can be increased irrespective of production costs or functional performance. The close association between professional design and commodity consumption also tends to undermine the potential of design to be used to promote and reinforce other forms of product exchange including sharing, borrowing and gift-giving.

Sign-value and meaning are also added to consumer goods by professional designers. The specic use of shape, form, materials, colours, etc is combined to provide an aesthetic and semiotic meaning for a product. However, in a capitalist economy, which depends on the rapid turnover of goods to survive, signs are very unstable. They are designed to be unstable or 'fashionable' and the in-built stylistic obsolescence of commodities is probably more powerful than technical obsolescence in aiming to encourage consumption. All commodities are now 'styled', more than fundamentally designed and, in a culture that encourages the rapid assembly and disassembly of signs as 
a basis of identity, status, and social acceptability, the result is increased consumption with its attendant ecological consequences.

Design also adds meaning in a more general way. Designed goods reflect the predominant social imperatives of the time. For example, product designers in the 1930s and again in 1950s were able to pronounce the supposed ideals of a technologically driven capitalist modernity by using various techniques and design motifs. These included streamlining and surface product decoration with allusions to speed, power, atomic energy, space technology, and so on. In the $1950 \mathrm{~s}$, curtains were printed with patterns taken from X-ray crystallography, coat racks resembled molecular structures and, car dashboards were designed to mimic the popular science fiction representations of spaceship control panels. The products looked modern and the act of consumption bestowed the values of modernity onto the consumers themselves. However, the chief aims of such styling were partly to prepare for and partly to encourage a substantial increase in the consumption of mass produced, standardised consumer goods. It was one aesthetic component of the mode of regulation of Fordist production (Lee 1993, Gartmann 1994). Similar points can be made in relation to the eclectically styled post modern consumer goods that predominate today, with their allusions to different times and places. They generally reect the fragmentation of time and space that is characteristic of the post modern 'condition'.

Similar arguments can be made about design in relation to the idea of green products and a green aesthetic: design can be instrumentally deployed in order to convey a set of 'green' meanings behind which increased and ecologically damaging consumption can be encouraged. Consequently, there is a lot of interest being shown by many producers in product design and promotion that emphasises ecological credentials. The high social status accorded to professional 'consumer-led' designers in consumption intensive societies allows them to operate in harmony with these imperatives. They give nothing up by choosing to promote the role of design and green commodities in a selfreforming 'green' capitalism (Whiteley 1994). Designers tend to hide behind their own jargon, rhetoric and pseudo psychological/sociological posturing in order to preserve their exalted positions in a economy which depends upon them finding novel ways to maintain high levels of consumption. As Billet observes '.. it is rare to find designers who believe in less design, in terms of less products, less variety, less novelty and a life style of "conspicuous thrift" - rather than the norm of "conspicuous consumption"' (Billet et al 1996: 3). 
The notion of a 'green' product aesthetic is also open to critical interrogation. The radical designer Victor Papanek argues that if products are designed for disassembly, reuse, repair, recycling, etc, a new 'green aesthetic' for products will emerge. This may be so but, it does not mean that powerful promotional industries cannot present a product aesthetic that claims to be one that incorporates certain criteria without the products themselves actually fullling those same criteria. ${ }^{2}$ After all, there was no practical need for many different household products to be streamlined in the 1930s, 40s, and 50s. These radios, refrigerators and vacuum cleaners did not need to move quickly through the air! The green consumer boom of the late 1980s played precisely upon this strategy. The bogus ecological credentials and specious environmental effects of a whole range of commodities were strongly promoted in order to appeal to the consumer's green feelings and sense of personal ecological empowerment. Hence green product styling can be used just like any other type; to obscure the social relations of production by filling the gulf of meaning in the commodity form which arises from the separation of production and consumption.

\section{Product-services}

There has been much recent speculation that the 'product-service', as part of a 'Service and Flow Economy', provides a green antidote to the overconsumption of tangible objects. Increased consumption of services is regarded as decreasing the need for consuming as many resource depleting manufactured goods. The kind of services that are seen to be ripe for increasing commodication and as matrices into which products can be embedded include: cleaning, repairing, upgrading, transport, spare parts, information services, and so on. These service options are seen to add up to concepts such as 'Value Added Manufacture' (VAM) and the like. Increasingly, the emphasis is often upon the leasing of a service rather than on a physical object; clean clothes and not washing machines, the "warmth, beauty and comfort' of 'floor-covering services' rather than carpets (Hawken et al 1999) It is envisaged that the consumer would take out various service contracts,

\footnotetext{
${ }^{2}$ Travellers returning from exotic locations with toys that appear to be made from recycled drinks cans (the creatively scavenged waste of multinational corporations?) may be interested to learn that these souvenirs are usually made from aluminium or steel sheeting pre-prepared with the decals of the drinks brands alluded to.
} 
insurance policies, warranties, and guarantees when purchasing a product and/or, that the product itself would be leased rather than purchased outright. These arrangements already obtain in some sections of the automobile and domestic goods markets and many retailers now make more from the sale of warranties than they do from the goods themselves (Tims 1998).

Consequently, there is increasing talk of 'embedding' products within service webs with the explicit aim of maintaining business turnover that would be lost through decreasing commodity production and consumption (van Hinte 1997). One leading designer and commentator who advocates the development of these 'product-services' puts it succinctly, 'Now that markets are saturated and there is a relevant need for virgin ones, we must see that this could be an outstanding ground for a new generation of products and services' (Manzini 1997: 219). There is a further suggestion that not only could product-services maintain turnover but, that because of the supposed decreased ecological impact of services they could actually lead to increased consumption. Hafkamp (1997) gleefully suggests that consumption can be doubled whilst ecological impact is halved. Such claims deserve critical attention.

\section{The myth of immateriality}

The notion that services, by their very nature, have less malevolent ecological impact needs to be analysed in more detail. Exactly which services are ecologically less degrading and in which ways? There is often an unexamined assumption that services are somehow 'immaterial' and therefore do no eco-

logical harm. Such an assumption is spurious. The environmental costs of transport associated with the provision of goods and services, for example, may be very high. The growing home Internet shopping phenomenon has spawned new fleets of polluting delivery vehicles. Or, imagine the situation in which constant streams of service engineers of one sort or another perpetually ferry themselves from house to house, and product to product, cleaning, repairing, upgrading, and so on. Many of these services also depend on material products (tools, cleaning materials, spare parts, etc) which all have to be produced somewhere by someone with their attendant ecological impact. The provision of services could, in this way, actually lead to increased product consumption which has been displaced from the domestic to the service sphere. 
The ecological claims made for 'immateriality' are made most explicit when referring to those services, such as product information, that can be provided electronically. However, such assumptions are again rather naive and specious. All of the virtual information realms, the Internet, WorldWide-Web, e-mail, etc, depend upon the materiality of the computer technology which generates them (Moles 1995). There is a wealth of evidence concerning the ecological degradation and anti-human social consequences associated with the computer industries (Hayes 1989). Moreover, the computer industry is one which actively promotes the gratuitous replacement of still functioning machines with 'better', 'faster' models. A society-wide move to the embedding of products within services may require a massive expansion of both production and consumption of the computer and other information technologies needed to access the required information. Indeed, many providers of information services particularly Internet Service Providers (usually subsidiaries of established telecommunications enterprises) already 'give away' the hardware. Personal computers are given in exchange for loyalty to a particular ISP for a certain period of time, usually several years. The revenue generated through providing these 'virtual' services more than offsets the current retail price of the hardware. Computer helplines, for example, often charge calls at the highest tariff possible. This is combined with the monopoly of technical expertise that resides with the call operators. The result is that consumers stay on the line for long periods of time to be instructed in very basic procedures. The revenue from such service provision is increasingly more signicant to manufacturers than basic hardware provision. This situation is mirrored in the mobile phone sector. However, there, the bewildering array of tariffs and service options that tie consumers to particular networks are 'compensated' by the proliferating choice of phone models themselves. Options are huge with hundreds of models in many different shapes, colours and sizes. This industry offers personalised consumption of 'product' within a very limited and contractually tight 'web' of services. In general, then, hardware is increasingly seen as a disposable by-product of service provision. One result may be growing indifference concerning the ecological impact of hardware manufacture and disposal.

Increased consumption of services is not a guarantee that service producers can escape the political economy of capitalist social relations. Quite the reverse. Just because services are non-material goods (in the limited sense identied above) is largely irrelevant. They are commodied services and are 
hence subject to the same contradictory political-economic dynamics that govern the automobile, fizzy drink or banana industries. There will be periods of over-production and under-consumption of services, there will be unfulled demand and restricted supply at times, there will be competition between service providers for scarce service markets. Such competition may result in price fixing agreed between service providing cartels or, to the consolidation of monopolies. These are already identiable features of various information services. For example, the number of Internet Service Providers has grown massively in the last year. Competition revolves around access costs to the Internet and the provision of various tariffs, tie-ins and information services 'tailored' to individual requirements. The expansion has been so massive and rapid that many ISPs are already being forced out of business as consumers switch between brands in search of the best deals. The distorting inuence of British Telecom's near monopoly in the United Kingdom, in terms of telephone access to the Internet, also has an effect. The signicant point about ISPs are that they are the most 'de-materialised' of services. There need be intimate connections to specic makes or models of consumer products, just to personal computers generically. Furthermore, there are no servicing or repair aspects to such services that would require components or tangible products. Indeed, there is often no provision of information services either, just simply access to the world of 'on-line' information. If capitalist social relations result in competition between the virtual' services themselves then, the idea that product-service 'webs' would avoid these effects and result in ecological benefits appears fanciful.

\section{Obligations and 'autonomy'}

Another result of service provision competition is increasing pressure to maximize revenue through failing to fulfill ill-dened servicing obligations. There is certainly a good deal of concern over the ways in which various warranties and guarantees are used to fleece consumers. In United Kingdom law, for example, there is no agreed denition either of warranty or of the notion of "wear and tear'. This gives great power to manufacturers to determine when goods need to replaced (Tims, ibid). Moreover, limited insurance coverage at high prices, constricted periods of cover, exclusion clauses, and service charges far in excess of reasonable repair and replacement costs, all represent ways in which the saturated and highly competitive service provision industries 
increase revenue and profits, often under a veneer of 'green' verbiage.

There is also some rhetoric abroad that promotes the idea that such product-service webs would allow the individual customising of productservice congurations. This is regarded as empowering and ecologically benecial. However, whilst such individualised customising may be formally possible (although one might seriously question the signicance of such a 'freedom' for most people) it is likely to be very limited in practice. The lack of technical compatibility between similar products manufactured under different brand names by different producers works against customising. The fact that incompatible products are often actually manufactured by sub-divisions of the same parent company indicates the such brand competitiveness is often an engineered procedure to encourage either consumption through both loyalty to a particular brand and its attendant services or through brand switching on the basis of spurious technical or stylistic 'improvements'. As a result, customising, which implies a high level of autonomy of action, is restricted by producers to a sphere defined by their products, components, and services. To distort the famous Fordist maxim: 'you can have any model or service you want, so long as it's ours'.

The 'product-service' is still a commodity or, rather, a bundle of commodities. Surrounding a product with a number of service options, or perhaps even requirements on the part of the consumer, can be viewed as not only increasing consumption (of services at least) but also as a means of tying consumers ever closer to the institutions, regulations and financial imperatives that govern consumption. Many of these product services can be seen as a kind of product mortgage which ties the consumer to a particular product, brand, or corporation for large portions of their life. If domestic products are leased or purchased on extremely long term arrangements, not only is it likely that a lot more will have to be paid for them, it also tends to undermine what limited autonomy exists in the realm of consumption. In the future there may even be penalties incurred on the part of consumers if they try to provide some of the service options for themselves (eg, minor repairs, as already applies to many 'high-tech' goods such as personal computers which offer numerous 'no user serviceable parts inside' warnings) or, if they wish to break long term contractual arrangements. Tying consumers closer to their commodities via contractual service agreements may suggest certain ecological benefits but, it also raises the prospect of people being incorporated ever tighter within heteronomously imposed consumption patterns. It is certainly 
ironic that many environmentalists who condemn personal consumption as the cause of ecological damage should proclaim that the solution is to bind people physically, emotionally and financially more closely to the world of commodities. ${ }^{3}$ People may increasingly spend their lives and incomes on absorbing externalised production costs within an ideological framework which locates both environmental destruction and ecological 'healing' in personal consumption. Product-services foster an ideology of the 'caring consumer' and aim to instil guilt, shame and anxiety in people for their supposed individual responsibility for environmental despoiling (van Hinte 1997: 223).

\section{Design for Disassembly}

'Design for Disassembly' (DfD) advocates the use of recycled materials and reused components, design that facilitates ease of disassembly and, a product's recycling at the end of its 'life' (sic). It is argued that reasonable quality components can be refurbished or reused, that metallic parts can be easily separated so increasing their recycling value, that disassembled plastic parts can be easily removed and recycled, and that parts made from glass or hazardous materials can be easily separated and reprocessed. Consequently, proponents of DfD recommend that various features be integral to finished manufactured goods. These include that all parts should be clearly marked and easily removed, that the number of joints, attachments and fasteners be minimised, that the number of tools needed for disassembly be minimised and standardised, that the highest value parts be the most easy to locate and remove, etc. Concepts such as 'Intelligent Product Systems' abound.

At present disassembly, where it does occur, is mainly undertaken by either the original manufacturer of the product or by a company having a contractual arrangement with the manufacturer. However, disassembly usually does not result in economic recycling because the cost of disassembly often outweighs the revenue gained through recycling the disassembled parts and materials. For example, the disassembly and recycling of automobiles is just profitable in the case of metal components but is extremely unprofitable with respect to the glass, foam, rubber, and battery components (Hacker 98).

\footnotetext{
${ }^{3}$ One inuential designer aims for us all to treat our consumer products with such tenderness that they come to represent a 'garden of objects' (Manzini 1995). In reality, this sentiment has simply been translated into a modish form of 'organic' product styling.
} 
One way that the costs of disassembly could be reduced by manufacturers is by off-loading them onto the consumers of these manufactured goods. Legal requirements for home disassembly (resembling those for domestic separation of refuse that already apply in some European states) would reduce costs and may aid in boosting the relative revenue obtainable through recycling and remanufacturing. DfD construction guidelines certainly lend themselves to the notion of consumer disassembly. The time taken for disassembly of products in industry is being increasingly monitored, evaluated and rationalised in order to decrease the disassembly turnover time. Hence, the prospect of alienating assembly-line disassembly work (perhaps outworking) becomes an attractive possibility to manufacturers, as does the prospect of domestic disassembly.

\section{DfD and recycling}

What of the components, parts and materials that result from DfD? Recycling is the general aim of DfD and, in much of the literature concerning these design techniques there is little consideration of the political economy of recycling. It is largely an unexamined practice and one which is assumed to be ecologically desirable. However, the recycling of components from disassembled products is prone to the same economic and ecological contradictions that befall product-servicing and waste re-valorization in general. At present regulation of recycling has resulted in specialist facilities devoted to particular and specic areas or types of products. And, currently, the responsibility for recycling has been laid at the door of the producers. One result of this is that there is the prospect of the proliferation of small, underutilised recycling facilities that receive relatively small flows of products (a specific model of refrigerator or, only kitchen appliances containing a heating coil, etc). The ecological benefits of recycling could be easily undermined by the energy input and pollution output that maintaining multiple facilities of this kind entails. Conversely, centralised recycling by the manufacturers of a product can result in increases in costs and ecological degradation due to increased transportation distances between recycling plant and the point where a product is discarded. For example, many German motorcars now have to be returned to Germany for recycling rather than be scrapped and recycled in British facilities (Potter 1993). This is because of legal directives such as Producer Responsibility (PR) which legally requires producers to be 
responsible for a product throughout its whole life. In order to off load the costs associated with PR, many producers now rely on third parties to do the recycling of products. These intermediaries between consumer and producer recycle components and materials for profit, hence competition between firms in the recycling sector grows with all the attendant political-economic contradictions that such inter-firm competition generally exhibits. Competition results in both price competition for recycling services and in the cutting of costs to make such competition viable. ${ }^{4}$ The ironic result, apart from all the normal measures of wage cuts, job losses, flexible contracting, etc, is the diminished attention paid to the ecological degradation of recycling practices themselves. Recycling can be expensive and can itself produce large amounts of wasted energy and polluting materials. In times of price competition the full environmental costs of recycling are unlikely to be reflected in the general costs of recycling. They often become externalised as increasing pollution of one form or another.

It is also often also the case that the claims made for the environmental desirability of strategies such as recycling compare very badly next to the ecological harm caused during manufacture or use of the goods in question. The increasing impetus placed on the recyclability of motorcars is a case in point. Even when reachingfigures of $80-90 \%$ recyclability, the ecological benefits of such strategies pale in comparison to the ecological damage caused by motorcar emissions. Hence, these strategies can be promoted as a kind of smokescreen in front of which manufacturers can claim high levels of concern for the environment, whilst behind it they are paying relatively scant attention to the most ecologically damaging phases of a product's life cycle.

\section{Conflicting values}

At the centre of a critical analysis of product strategies such as DfD is the denition of value accorded to these material artifacts by different social groups. For environmentalists and reforming product designers, these disassembled bits and pieces represent attempts to chart a course out of the environmental

\footnotetext{
${ }^{4}$ This has been the case within the British textiles recycling sector over the last year. A general downturn in the global textiles economy combined with the aggresive intervention of the USA into the textiles recycling sector have driven down costs and froced down prices in the British sector. There is a widespread fear of a consequent recession in this 'green' industry.
} 
quagmire which they see as deepening around us. These various components are seen as having an ecological value which is assumed to be intrinsic and transparent to all. However, for a manufacturer looking to sell products in a competitive market, these very same components are likely to be viewed differently They are raw materials and, assuming they are functionally acceptable, are likely to be regarded as valuable in other, distinct ways. Firstly, as cheaper components whose full costs of manufacture may belong to a distant cycle of commodity production and, secondly, as lucrative raw materials that can be used to secure higher future revenue due to the flexible manner in which the products of DfD can be deployed. Their practical and symbolic environmental value is unlikely to be given much accord in comparison.

For example, in general, most of the disassembled parts resulting from DfD have a relatively small recycling value (hence, the need for the most quick and easy disassembly) as individual components. However, once refurbished and recombined into 'new' products they attain increased market value. This is especially the case if the old components are assembled within a new, aesthetically pleasing and desirable shell; refurbished telephone components hidden within a sophisticated and technologically advanced looking body, for example. Several questions arise in relation to the development of such practices: How could re-valorised components in brand 'new' commodities be identied by consumers? Would there be a legal requirement for the labelling of products containing the DfD components of previous products? Would a telephone partially manufactured from previously used DfD components be substantially cheaper (reflecting its decreased costs of production) than one manufactured from 'virgin' components? Maintaining the high cost of commodities benfiting from previous DfD would be an obvious method of increasing both revenue and profit as costs of production would fall relative to market price. In effect, consumers may pay several times over for components that have been recycled through circuits of productionconsumption-'destruction' who knows how many times?

Strategies such as DfD could actually lead directly to increased product consumption with its associated environmental impacts. We may witness big promotional campaigns to encourage people to replace their non-DfD, ecologically malign goods with the DfD, ecologically more benign replacements. DfD could be promoted as an environmentally friendly, chic and desirable aspiration. Manufacturers could cannibalise and revalorise the old non-DfD goods so avoiding or offsetting landll costs. This could make fur- 
ther cycles of re-valorizing easier and more efcient as DfD becomes more widespread. Moreover, DfD does not prevent capitalists from continuing to use obsolescence (both technical and stylistic) in order to encourage further consumption. DfD goods could still be made to wear out prematurely thus necessitating replacement. Equally, product styling could be used to give the idea that particular models of a DfD product are no longer aesthetically desirable thus encouraging further consumption.

There is a technique that mirrors DfD that has also been suggested as an ecologically benecial alternative to buying finished products. This is the widespread use of kit buying. It is argued that assembling our domestic products from kit form would lessen consumption as our appreciation and familiarity with our products would increase through the act of self-assembly (Papanek 1994, 1995). Overall consumption would also diminish, it is claimed, as familiarity with modular kit-form products would allow minor home repair as well as encouraging safer and more enduring use of these products. Kit buying is already a common feature of products such as flat-packed furniture or Hi-Fi equipment which require some self-assembly. How satisfying this is or, how much it teaches people to value lower levels of consumption is open to speculation. What does become clear is that kit-form goods can be partially seen as a way of passing on the assembly costs to unpaid consumers. Not only are costs offset in this way but, from the Weberian perspective of Ritzer identied above, such strategies also represent an increase in the general level of surplus which can be drawn on a society wide basis. Increased profits and reduced production costs may be one aimed for outcome of this type of approach. For capitalists this is an ideal prospect of consumers building, disassembling and recycling the same components into different commodity congurations whilst paying several times over for the privilege. Looked at another way, it is a vision of a capitalism in which people increasingly produce commodities away from, as well as in, the formal productive sphere. People increasingly work when they are not at work, only they receive no wages. It is equivalent to paying someone else and then mowing the lawn yourself!

\section{Re-valorising rubbish}

This involves taking discarded commodities or components of commodities and re-valorising them by turning them into new sets of desirable commodities. Examples from a recent exhibition include jewellery made from dis- 
carded sweet wrappers, handbags fabricated from used and dried tea-bags, lampshades assembled from 'discarded' film negatives or milk bottles and, furniture made from crushed aluminium cans. Its success centres around the realisation that waste is an abundant though largely ignored raw material. However, this is a different strategy to others that focus on waste - repairing, reusing and recycling. Repairing is basically the selling of a service to prolong the functional life of a commodity. Reusing can cut costs for capitalists but does not generally stimulate extra consumption of that particular commodity, for example the milk bottle. Recycling, defined as the partial or complete breaking down of components or materials and their re-combination or reuse as new commodities, can both save and incur costs of production. It tends to be short-term with a highly limited number of recyclings being practically possible, for example, turning plastic bottles into fibres for clothing. Revalorising rubbish seems to promise something more: taking something that would probably not be repaired, reused or recycled, but discarded as rubbish, and adding value to it. New features can be added, new congurations can be engineered, new commodities produced. This is not a new strategy per se. Many commodities that are taken for granted are the outcome of such re-valorization strategies. Pet food, for example, is an incredibly lucrative method of turning waste into profit. What is new is the extension of such practices into the wider domain of the commodity environment. Functional household products are regarded as the new arena in which re-valorization of rubbish could be deployed. Moreover, the use of design to add symbolic value and ecological meaning to such commodities marks these contemporary forms of re-valorization as novel.

Re-valorised rubbish is able to play successfully on notions of repair, reuse, and recycling, as well as seeming to profess an acute and benign ecological sensibility. It does this through the way it is promoted, in terms of its attendant advertising, the cultural discourses surrounding it (usually of the middle class technocratic, green reformist type) and, via the meanings displayed in the product styling used. Elements are included that resonate with the most well known ecological themes. For example, the use of identiably recycled elements, wood, plastics, packaging materials, tin cans, and so on. Similarly, the use of supposedly internal components as external features, often juxtaposed in intriguing and novel ways, can suggest that a rupture with the normal cycle of commodity production and destruction has occurred. This usually is not the case: what is actually happening is the design, development 
and production of new commodities that do not break with the logic or ecological consequences of commodity production or destruction. Indeed, they may well exacerbate this logic, as well as promoting increased consumption.

A concrete example of re-valorizing of rubbish into a desirable new commodity is insightful. Interested and enthusiastic shoppers can now purchase four washing machine drums recombined into a four compartment cabinet called a 'Robo-Stacker'. Little adaption of the original components, scant evidence of complex processing or of high production costs is apparent yet, this new commodity sells as an expensive high class piece of furniture. The price is many tens that of the cost of four washing machine drums. Consumers are presented with a seductive, quirky, and intriguing product which seems to carry strong messages of recycling and a commitment to ecological balance. However, these pieces of furniture are not actually made from discarded drums from defunct, discarded or disused washing machines. Rather, they are manufactured, under sponsorship from a multinational domestic goods manufacturer, from drums that have not passed quality control tests. The drums used in the 'Robo-Stacker' have never been anywhere near a working washing machine. Hence, there is a deceit taking place in terms of the meaning conveyed by the product itself. Moreover, the ecological claims themselves are spurious. The product relies on needless production of the drums themselves. The drums are scavenged from one part of the production cycle of washing machines. Hence, the makers of the 'Robo-Stacker' are reliant on a steady flow of drums that fail the quality control procedures. This works against the drum manufacturer's motivation to improve the output quality. A specific form of waste has to be guaranteed as a raw material for these re-valorised commodities. Interestingly, the name of the drum manufacturer appears on the drums even though the furniture is manufactured by a small design group. The drum manufacturer benefits from the association with the conveyed images of reuse and recycling. Signicantly, though, the drum manufacturer's name does not appear on the drums that actually go into washing machines. That is, the company does not brand its real rubbish, just its pretend rubbish!

This example reflects a recent growing interest amongst small design groups for found objects and materials being fashioned into new designs and products. Such creative scavenging and vernacular use of materials usually results in one-off or very small batch production. In relation to the themes of this paper, problems occur when small runs of such products prove to 
be commercially successful. The temptation is to start to manufacture large numbers of objects that look as though they might have been found. There is the prospect of emerging mass production of supposedly, unique, vernacular, and found objects. It is established multinational corporations that are best placed to deal with such economies of scale, something they are beginning to realize. Indeed, many of these results of creative scavenging and small-batch production are willingly incorporated into the economies of scale of big business. Large scale manufacture reduces production costs, provides increased resources for research and development, and vastly increases advertising revenue. However, it also then produces the need for ever-increasing amounts of raw materials, in this case specic forms of waste. There is also likely to be competition from other large manufacturers of such products leading to further pressure to reduce production costs through cutting 'green' corners. Pressure for cost reduction in production may see such firms increasingly aiming to externalise their costs in the ways already considered. In short, the resulting mass produced green products-from-waste become caught up in the same kind of contradictory political-economic processes that characterise capitalism in general. Of course, these producers are likely to be the very same corporations who continue to manufacture more ecologically damaging products alongside the 'green' lines.

As most of these new commodities are high price 'life-style' products, there is every reason to believe that they too will be subject to the same processes of stylistic obsolescence as those commodities they profess to replace. It is also the case that 'replacement' materials, whilst offering the prospect of less ecological damage, are only a purchasing option for the well off. Traditional craft techniques of production, small batch production, combined with their promotion as cosmopolitan 'life-style' products results in a very low social distribution of these preferable (in environmental terms) alternatives. The production of hemp, nettle and peat fibres as alternatives to bleached cotton or, the promotion of 'natural' grass floor coverings as an alternative to carpets are two expensive examples.

\section{Conclusion}

The oxymoron 'green' commodity is both accurate and apt. Green has come to imply self-limitation, of resources, energy, materials, environmental impact, and the like. However, commodification, by its very nature, is not 
a self-limiting social process. This does not imply that the strategies discussed here are somehow 'bad'. One can immediately see the ecological sense of products that are more durable, use less resources, can be recycled and reused, and have less environmental impact in a number of ways. Hence, we may be able to talk of 'green' products but, within the social relations of capital accumulation those products which are manufactured as exchange-values for the market are by their very denition commodities and are not subject to the self-limitation that the term 'green' implies or that these product strategies suggest.

The strategies of valorisation discussed above by themselves do nothing to lessen dependence on the market for the satisfaction of human needs. Of course, in a general sense, 'eco-strategies' that encourage consumption as a means towards sustainability simply repeat the idea that, through the market, money can be the most powerful vote for desirable social change. Such strategies say nothing to the impoverished who cannot participate. They form part of a blueprint for social change driven and directed by the affluent middle classes, managers, technocrats, designers and any number of authoritarian ecologists who are willing and able to pay the full 'ecological' costs of production. This is especially so when attention is focused upon the consumption of 'exclusive' and 'individualised' cosmopolitan 'life-style' products. Poorer sections of society, whilst having to endure relatively higher levels of poorer quality goods, may also find themselves bearing the bulk of the social costs of such ecological strategies through the increasing regulation and policing of their practices of consumption, use and discarding of goods. ${ }^{5}$ The denition of new 'green' needs would have to be increasingly stimulated and then assuaged with the promised satisfactions of ever newer and sophisticated 'green' commodities in order to maintain a dynamic and expansive political economy.

Questions also arise in relation to the practical impact that such product strategies could produce. In a typical year in the United States alone over

\footnotetext{
${ }^{5}$ Leasing, for example, is already commonplace as a means of owning certain goods including televisions and video recorders. People on lower incomes often have this as their only means of securing access to these goods. However, the costs incurred via this kind of ownership far exceed the average retail costs for such items. Moreover, the idea that leasing of this kind leads to manufacturers and retailers providing the most durable, well designed and environmentally benign commodities is contentious. It is often reconditioned, pre-owned and older, less energy and resource efficient models that are made available for leasing or renting.
} 
17,500 new products are launched (Sale 1996). How many of these would lend themselves to such techniques? How many manufacturers are going to risk the initial expense involved knowing as they do that a high proportion of new commodities are no longer in production after just one year? Economies of scale tend to reinforce the suggestion that such product strategies could be effectively introduced in only a few areas; high status, relatively shortrun, expensive 'life-style' products or, conversely, relatively stable, long-run, mass production goods with only incremental model changes. Concretely, this means that such strategies may be applicable to items such as expensive table lamps on the one hand and to refrigerators or washing machines on the other. Most of the products currently manufactured are neither such exclusive domestic luxuries nor mass, long-run products composed of clearly defined and separable components. One thinks of the clothes industry which is largely driven by the fashion system, or any canned goods industry or, the videotape industry. A quick glance around most domestic interiors quickly reveals that only a small proportion of manufactured goods fall in to the neat categories devised by the proponents of these new product strategies. The proliferating density, complexity and scale of objects that form our every environment -work, domestic, leisure- tends to undermine one's faith in such techniques.

We should also not neglect the social relations of production underlying these supposedly sustainable and environmentally benign commodities. They too, form part of the 'dirty secret of capitalism'. Factories or workshops of wage labourers assembling such products do not have any essential claim to be qualitatively better or less exploitative than any other capitalist production process even if the finished commodities themselves suggest this is so through their 'green' commodity aesthetics. A similar point can be made in relation to the growth of 'de-materialised' services. Working conditions in many sectors of the information services industries are notoriously exploitative. Intensive and long shifts tending phones in call-centres are associated with stress, high levels of surveillance and the 'corrosion of character' (Sennet 1998) Truly sustainable products and services would rest on non-exploitative social relations of production as much as on environmentally just processes.

Repair, recycling and reuse can, of course be part of the autonomous satisfaction of needs in relation to the products necessary for life. Many of the practical repair skills practised by previous generations have been lost, as have many of the small traders who provided such skills. This loss of skills is 
partly explainable by over-dependence of commodities provided by the market, with the attendant stylistic and technical obsolescence that drives such provision. It is also due to the design of many commodities themselves which increasingly separates engineering from surface decoration components, often rendering access to the repairable parts difficult if not impossible. Moreover, there is a nuanced yet persistent ideological background which subtly links repair, thrift and reuse to notions of preindustrial, backward, parochial and regressive attitudes. Conspicuous consumption and disposal is regarded as a healthy sign of material abundance and progress. However, when the skills needed to effect simple repairs to a whole host of diverse products are learnt and applied without recourse to market provision, they become the means by which a particular form of value, namely use-value can be added and extended with regard to materials that may otherwise have to be discarded in favour of the purchase of new commodities. The imaginative development of utility and the vernacular recycling of products and materials has always been an important, though largely unacknowledged, feature of the interaction between humans and the artifactual material culture they fashion for themselves. Traditional working class cultures have especially regarded these skills as a signicant element of the embodied practical know how of everyday life. The massive popularity of Do-It-Yourself (DIY) is interesting in this respect. The form of much DIY is thoroughly alienated depending as it does on the commodified provision of materials and the injunctions of 'experts' and 'designers' through the mass media. However, the content of DIY, that is, working directly, intuitively and creatively with physical matter, corresponds to real human needs and, in an alienated form, represents the potential realisation of human 'species-being' through direct sensuous engagement with the material world.

Manufacturers have shown relatively little interest in other possible product strategies: sharing, borrowing, co-ownership, second-hand use, product libraries, and so on. Sharing, and other forms of co-ownership, represents fewer products, fewer productive resources, less packaging, lower transport costs, reduced service costs, etc. Instead, mass personal ownership of goods whose communal or joint ownership makes much more ecological and social sense (including lawn mowers that lay idle for most of the year, ladders, hand tools, etc) is strongly encouraged. These other approaches to product ownership also pose the threat of stimulating and reviving the communal and collective sensibilities and autonomous competence that privatised con- 
sumption has strongly undermined over the past forty years. What these other approaches share is a lessening of individual, mass ownership of consumer commodities and it is this that socialists could promote as one basis for tackling the ecological riddle of capitalism.

\section{References}

Barry, J. (1999) 'Marxism and Ecology, in A. Gamble, D. Marsh, and T. Tant (eds.) Marxism and Social Science. MacMillan, London.

Billet, E. et al (1996) 'Editorial notes', in co-design 516: 1-4.

Cooper, T. (1997) 'Consumers, costs and choice', in E. van Hinte Eternally Yours: Visions on Product Endurance. 01 Publishers, Rotterdam.

Daly, H. (1977) 'The Steady-State Economy What, Why, and How?', in D. Pirages The Sustainable Society: Implications for Limited Growth. Praeger, London.

Dobson, A. (ed.) (1991) The Green Reader. Andre Deutsch, London.

Ekins, P. ed. (1986) The Living Economy. Routledge, London.

Elkington,J. \& Burke,T.(1987)‘Green capitalism’,in A.Dobson (ed.) (1991) The Green Reader. Andre Deutsch, London.

Elkington, J. \& Hailes, J. (1988) 'Green consumerism', in A. Dobson (ed.) (1991) The Green Reader. Andre Deutsch, London.

Gartman, D. (1994) Auto Opium: a Social History of American Automobile Design. Routledge, London.

Goggin, P. (1996) 'Glossary key concepts and definitions', in co-design 516: 5-7.

Gorz, A. (1980) Ecology as Politics. Pluto Press, London.

Gorz, A. (1982) Farewell to the Working Class. Pluto Press, London.

Gorz, A. (1985) Paths to Paradise: On the Liberation from Work. Pluto Press, London.

Gorz, A. (1994) Capitalism, Socialism, Ecology. Verso, London.

Hacker, S.(1998) 'Pickup the pieces', in G2, The Guardian, August 24:16-17. 
Hafkamp, W. (1997) 'Immaterilaization', in E. van Hinte Eternally Yours: Visions on Product Endurance. 01 Publishers, Rotterdam.

Harvey, D. (1996) Justice, Nature, and the Geography of Difference. Blackwell, Oxford.

Hawken, P., A. Lovins and H.L. Lovins (1999) Natural Capitalism. Earthscan, London.

Hayes, D. (1989) Behind the Silicon Curtain. Free Association Books, London.

Illich, l. (1973) Tools for Conviviality. Calder Boyars Ltd., London.

Lee, M. J. (1993) Consumer Culture Reborn. Routledge, London.

Lodziak, C., and J. Tatman (1997) Andre Gorz: A Critical Introduction. Pluto Press, London.

Manzini, E. (1995) 'Prometheus and the Everyday', in V. Margolin and R. Buchanan, (eds.) Discovering Design. University of Chicago Press, London.

Manzini, E. (1997) 'Leapfrog strategies: towards new service combinations', in E. van Hinte Eternally Yours. Visions on Product Endurance. 01 Publishers, Rotterdam.

Maycroft, N. (1996) 'Papaneks green imperative', in co-design 516: 103-7.

Moles, A. (1995) 'Design and Immateriality What is a Post Industrial Society?', in V. Margolin and R. Buchanan, (eds.) The Idea of Design. The MIT Press, London.

Papanek, V. (1994) 'Design, environment and social quality', in J. Myerson (ed.) Design Renaissance. Open Eye, Horsham.

Papanek, V. (1995) The Green Imperative: Ecology and Ethics in Design and Architecture. Thames \& Hudson, London.

Pearce, D., A. Markandya and E.B. Barbier (1989) Blueprint for a Green Economy. Earthscan, London.

Potter, S. (1996) 'Transforming Frigidaire', in co-design 516: 81-3.

Ritzer, G. (1998) The McDonaldization Thesis. Sage Publications, London.

Ritzer, G. (1999) Enchanting a Disenchanted World: Revolutionizing the Means of Consumption. Pine Forge Press, London. 
Sale, K. (1996) Rebels Against the Future. Quartet Books, London.

Sennet, R (1998) The Corrosion of Character: The Personal Consequences of Work in the New Capitalism. W. Norton \& Company, London.

Strange, G. (1996) 'Which Path to Paradise?: Andre Gorz, Political Ecology, and the Green Movement', in Capital \& Class 59: 81-102.

Tims, A. (1998) 'Empty promises', in G2, The Guardian, October 15:14-15.

Van Hinte, E. (1997) Eternally Yours: Visions on Product Endurance. 01 Publishers, Rotterdam.

Wallerstein, I. (1997) 'Ecology and Capitalist Costs of Production: No Exit', Keynote address at PEWS XXI, 'The Global Environment and the World System', Univ. of California, Santa Cruz.

Whiteley, N. (1994) Design for Society. Reaktion Books, London. 